\title{
Evaluation of a primary care paramedic STEMI bypass guideline
}

\author{
Jonathan L. Kwong, MSc*; Garry Ross ${ }^{\ddagger}$; Linda Turner, $\mathrm{PhD}^{\ddagger}$; Chris Olynyk ${ }^{\S}$; Sheldon Cheskes, $\mathrm{MD}^{\dagger \neq}$; \\ Adam Thurston, $\mathrm{RN}^{\S}$; P. Richard Verbeek, $\mathrm{MD}^{\ddagger \Uparrow}$
}

\begin{abstract}
Objective: Limited evidence supports primary care paramedic (PCP) direct transport of ST-segment elevation myocardial infarction (STEMI) patients for percutaneous coronary intervention (PCl). The goal of this study was to evaluate an urban-based PCP STEMI bypass guideline.

Methods: We reviewed consecutive Toronto Paramedic Services call reports between April 7, 2015, and May 31, 2016, regarding STEMI patients identified by PCPs. The primary outcome was patient assignment (stable versus unstable) according to guideline criteria. Secondary outcomes were the proportion of PCP-transported patients who had an indication for an advanced care intervention (ACl) or who received an $\mathrm{ACl}$ when $\mathrm{PCPs}$ rendezvoused with an advanced care paramedic (ACP). Lastly, we reviewed prehospital outcomes of cardiac arrest patients and calculated the difference in transport intervals between direct PCP bypass and a $\mathrm{PCl}$-centre and predicted transport interval to the closest emergency department (ED).

Results: Of 361 patients, 232 were PCP transports and 129 were ACP-rendezvous transports. There was a significant difference in the distribution of stable and unstable patients between PCPs and ACPs $(p<0.001)$. For PCP patients, $21 / 232$ (9.1\%) had indications for an $\mathrm{ACl}$, whereas $34 / 129$ (26.4\%) $\mathrm{ACP}$ patients received an $\mathrm{ACl}$. Eleven patients experienced cardiac arrest; 10 were successfully resuscitated ( 5 of these by PCPs). The median difference between direct PCP bypass and a $\mathrm{PCl}$-centre versus transport to the closest ED was 5.53 minutes $(I Q R=6.71)$.

Conclusions: We found a significant difference in the distribution of stable and unstable patients and fewer patients with indications for an ACl in PCP patients. This PCP STEMI bypass guideline appears feasible.
\end{abstract}

\section{RÉSUMÉ}

Contexte: Il existe peu de données étayant le transport direct, par les ambulanciers paramédicaux - soins primaires (PSP), de patients ayant subi un infarctus du myocarde avec sus-décalage du segment ST (STEMI) vers un centre en vue d'une intervention coronarienne percutanée (ICP).

Objectif: L'étude visait à évaluer une directive sur le transport direct, par les PSP, de patients ayant subi un STEMI vers un centre d'ICP, en milieu urbain.

Méthode: Nous avons passé en revue tous les rapports d'appels consécutifs, reçus par les Toronto Paramedic Services, entre le 7 avril 2015 et le 31 mai 2016, sur des patients ayant subi un STEMI reconnu par les PSP. Le principal critère d'évaluation était l'état du patient (stable ou instable) selon les critères de la directive. Le critère secondaire, lui, consistait en la proportion de patients transportés par les PSP et ayant une indication d'intervention en soins avancés (ISA) ou ayant subi une ISA au lieu de rencontre avec I'ambulancier paramédical - soins avancés (PSA). Enfin, nous avons examiné les résultats des arrêts cardiaques en phase préhospitalière, et calculé les écarts de temps entre le transport direct de patients, par les $P S P$, vers un centre d'ICP et le temps prévu de transport de patients vers le service des urgences (SU) le plus près.

Résultats: Sur 361 patients, 232 ont été transportés par des PSP et 129, transportés vers un lieu de rencontre avec un PSA. II y avait un écart significatif dans la répartition des patients stables et des patients instables entre les PSP et les PSA $(p<0,001)$. Parmi les patients transportés par les PSP, $21 / 232(9,1 \%)$ avaient une indication d'ISA contre $34 / 129(26,4 \%)$ pour les patients transportés par les PSA et soumis à une ISA. Par ailleurs, 11 patients ont fait un arrêt cardiaque et 10 ont été réanimés, dont 5 par les PSP. L'écart médian du temps écoulé entre le transport direct de patients, par les PSP, vers un centre d'ICP et le transport de patients vers le $\mathrm{SU}$ le plus près était de 5,53 minutes (écart interquartile $=6,71$ ).

Conclusions: Un écart significatif a été relevé dans la répartition des patients stables et des patients instables, et il y avait moins de patients ayant une indication d'ISA chez les patients transportés par les PSP. La directive sur le transport direct, par les PSP, de patients ayant subi un STEMI vers un centre spécialisé semble donc applicable.

From the *Department of Medicine; †Department of Family and Community Medicine, Division of Emergency Medicine, University of Toronto, Toronto, ON; ¥Sunnybrook Centre for Prehospital Medicine, University of Toronto, Toronto, ON; §Toronto Paramedic Services, Toronto, ON; and IS Sunnybrook Health Sciences Centre, University of Toronto, Toronto, ON.

Correspondence to: Dr. P. Richard Verbeek, Sunnybrook Centre for Prehospital Medicine, 77 Brown's Line, Suite 100, Toronto, ON M8W 3S2; Email: richard.verbeek@sunnybrook.ca 
Keywords: emergency medical services, percutaneous coronary intervention, prehospital emergency care, STsegment elevation myocardial infarction, STEMI bypass

\section{INTRODUCTION}

ST-elevated myocardial infarction (STEMI) management guidelines favour percutaneous coronary intervention (PCI) over other forms of reperfusion therapy such as fibrinolysis, especially when PCI can be performed in a timely fashion. ${ }^{1,2}$ As a result, prehospital systems $^{3,4}$ have developed whereby paramedics transport STEMI patients directly to PCI centres, often bypassing emergency departments (ED) of non-PCI hospitals. ${ }^{5,6}$

Published guidelines provide little advice regarding the scope of practice required by prehospital care providers to perform a STEMI bypass. The American Heart Association has stated that "providers should be trained to respond to cardiovascular emergencies, including ACS [acute coronary syndrome] and its acute complications." 7 This suggests that the scope of practice should include full advanced cardiac life support (ACLS) skills. Ultimately, these guidelines pertain to the safety of prehospital transport of STEMI patients where safety may be considered from the patient perspective as low risk of acute complications and, from a paramedic perspective, as being able to manage complications that do occur.

Recent reports have suggested that hemodynamically stable STEMI patients infrequently require advanced care interventions (ACI) and that primary care paramedic (PCP) transport of these patients may be safe. ${ }^{8-10}$ To add to the evidence, we evaluated a STEMI bypass guideline authorizing PCPs to perform a STEMI bypass for hemodynamically stable patients complemented by a consideration for advanced care paramedic (ACP) rendezvous/transport for hemodynamically unstable patients. Our objectives were to 1) assess PCP assignment of patients to PCP transport versus ACP-rendezvous according to stable versus unstable criteria, respectively, 2) compare the proportion of patients transported by PCPs having indications for an ACI with the proportion of patients receiving an ACI after ACP-rendezvous, 3) describe clinical aspects of patients who experienced cardiac arrest, and 4) compare transport intervals incurred by a PCP STEMI bypass, with or without ACP-rendezvous, with PCP transport intervals to the nearest ED.

\section{METHODS}

\section{Study setting and STEMI bypass guideline}

Toronto Paramedic Services responds to approximately 300,000 incidents annually and services 3.5 million citizens in a geographic area of $650 \mathrm{~km}^{2}$. It comprises approximately 1,100 paramedics (75\% PCPs and $25 \%$ ACPs). Of the 14 local hospitals, 6 are PCI centres. The range of distances from a non-PCI centre to its closest PCI centre is $0.1 \mathrm{~km}$ to $15.2 \mathrm{~km}$.

PCPs had been previously trained in 12-lead electrocardiogram (ECG) acquisition and STEMI recognition using manual, aided by computer, interpretation. The PCP STEMI bypass guideline was developed by a consensus working group of paramedics, emergency medical dispatchers, and the base hospital medical director. This guideline was implemented in April 2015 following a 3.5-hour paramedic training program. The guideline identified three groups of patients: 1) stable (normal vital signs); 2) unstable (heart rate $<50$ or $\geq 120$, systolic blood pressure $<80 \mathrm{~mm} \mathrm{Hg}$, or requires ventilation); and 3) diversion (unmanageable airway, or cardiac arrest with a non-shockable rhythm or no return of spontaneous circulation [ROSC], despite two defibrillations). PCPs were authorized to transport stable patients directly to the PCI centre or, for unstable patients, to inform dispatch to request an en route ACP-rendezvous, whereby dispatch advised a rendezvous location depending on the proximity of the ACP and PCP crews. PCPs were also authorized to request a rendezvous if they were uncertain of the appropriate course of action. If a rendezvous was not possible, the PCP continued transport to the PCI centre. Patients meeting diversion criteria were to be transported to the closest ED whether or not the receiving hospital had a PCI centre. Study approval was granted by the Sunnybrook Health Sciences Centre Research Ethics Board.

\section{Identification of cases}

STEMI cases were identified using a three-step approach. Firstly, the Toronto dispatch database was queried from April 7, 2015, through May 31, 2016, for all cases that cited "STEMI" as the main reason for transport. Secondly, all identified electronic patient care reports (ePCRs) were queried for a "STEMI positive" notation. Thirdly, we identified all ePCRs with an 
*****ACUTE MI**** statement from the GE/Marquette 12-SL software in the Zoll E-series defibrillator/ cardiac monitors (ZOLL Medical, Chelmsford, MA).

We then excluded all cases where a PCP was not the first paramedic to make patient contact. We also excluded cases where ACPs arrived at the patient's pickup address within 5 minutes of initial PCP arrival, assuming that PCPs would not have had adequate time to perform an initial assessment, acquire a 12-lead ECG, and arrange for an ACP rendezvous. Lastly, we excluded cases with a known "do not resuscitate" (DNR) order or a "STEMI positive" ECG interpretation occurring only after ACP arrival. The remaining PCP ePCRs were screened to ensure that at least one of the following conditions was documented:

1) The ECG was compatible with STEMI

2) The patient was being transported as a "CODE STEMI"

3) Actions provided indicating the patient was STEMI positive (e.g., a notation regarding patient transport to a PCI centre)

\section{Demographics and identification of advanced care interventions or cardiac arrest}

Patient demographic and clinical data were abstracted from ePCRs using standardized abstraction forms.

In cases of ACP-rendezvous, we recorded performance of any of the following ACIs outside the scope of practice of our PCPs: intravenous saline bolus; administration of atropine, dopamine, epinephrine, or amiodarone; intubation; synchronized cardioversion; and transcutaneous pacing. Cardiac arrest cases were reviewed to describe the clinical course, interventions performed, and prehospital outcome. Because defibrillation is within the scope of practice of PCPs, it was not considered an ACI. The ePCRs were reviewed to determine whether an ACI was performed (in the case of an ACP-rendezvous) or whether there was an indication for an ACI during PCP-only transport, based on current medical directives.

\section{Transport intervals}

Actual and predicted transport intervals were recorded for each patient. Actual transport intervals were determined from dispatch data that recorded departure time from the pickup address and arrival time at the destination. Predicted transport intervals were derived using mapping software (Patient Distribution System Estimated Transport Time Software) used by Toronto Paramedic Services emergency medical dispatchers. Actual transport intervals for patients transported directly by PCPs to the PCI centre included bypass of any hospital ED that was not a PCI centre. Actual transport intervals where an ACP-rendezvous occurred included the time required for rendezvous as well as bypass of a non-PCI centre(s). Actual transport intervals for diverted patients were defined as the time of departure from the pickup address to arrival at the closest ED.

\section{Data analysis}

Patient demographic and clinical characteristics are reported using descriptive statistics. Patient clinical status (stable v. unstable) and type of transporting paramedic crew ( $\mathrm{PCP} v$. ACP) were compared using the chi-square test. Transport intervals were described using medians and interquartile ranges (IQRs). All analyses were performed using SAS (Version 9.4, SAS Institute, Cary, NC).

\section{RESULTS}

Of the 726 cases initially identified, we obtained a final cohort of 361 cases (Table 1). Median patient age was 65 years; $72 \%$ were male. Median age and proportion (male) were similar between patients transported by PCPs compared to ACPs (data are not shown). In all, $64.3 \%(232 / 361)$ of patients were transported directly by PCPs, and 35.7\% (129/361) were transported via an ACP-rendezvous (Table 2). No diversion cases were identified. PCP guideline implementation resulted in a significant difference in the distribution of stable and unstable patients between PCPs and ACPs $\left(\chi^{2}\right.$ : $p<0.001)$. This appears to be mainly related to the difference in the proportion of stable patients with PCP transport compared to ACP transport (176/242; 72.7\% versus $66 / 242 ; 27.2 \%$, respectively).

Of the 232 PCP transport cases, 21 (9.1\%) patients met indications for one or more ACIs (Table 3). Two of the 21 patients received a normal saline bolus because they were transported by PCPs with additional skills in intravenous insertion and saline administration. In the remaining 19 patients, there were 27 indications for an 


\begin{tabular}{|c|c|c|c|}
\hline $\begin{array}{l}\text { Cases from dispatch } \\
\text { database }\end{array}$ & $\begin{array}{l}\text { Cases } \\
\text { removed }\end{array}$ & $\begin{array}{l}\text { Cases } \\
\text { remaining }\end{array}$ & Reason for removal \\
\hline \multirow{9}{*}{ Cases reviewed } & & 726 & Cases from April 7, 2015, through May 31, 2016 \\
\hline & 4 & 722 & No ePCRs available for these cases (missing data) \\
\hline & 198 & 524 & ACP-only cases removed \\
\hline & 99 & 425 & ACPs arrived first or $<5$ minutes after PCP arrival \\
\hline & 10 & 415 & PCP noted patient was STEMI negative \\
\hline & 30 & 385 & $\begin{array}{l}\text { ACP arrived before patient determined STEMI positive } \\
\text { by PCP }\end{array}$ \\
\hline & 10 & 375 & Call not related to STEMI \\
\hline & 4 & 371 & Blank ePCRs \\
\hline & 10 & 361 & $\begin{array}{l}\text { "Other reasons" } \\
\text { - Other EMS service transport } \\
\text { - Combined stroke and STEMI patient } \\
\text { - DNR } \\
\text { - Online medical direction dictated transport } \\
\text { destination }\end{array}$ \\
\hline Final data set & & 361 & \\
\hline
\end{tabular}

\begin{tabular}{|c|c|c|c|c|}
\hline & & Stable criteria & $\begin{array}{l}\text { Unstable } \\
\text { criteria }^{*}\end{array}$ & $p$-value \\
\hline & $\mathrm{n}$ & n (\%) & n (\%) & \\
\hline All & 361 & 242 (66.9\%) & 119 (33.1\%) & \\
\hline PCP transport & 232 & 176 (75.9\%) & $56(24.1 \%)$ & \\
\hline $\begin{array}{l}\text { ACP- } \\
\text { rendezvous }\end{array}$ & 129 & $66(50.8 \%)$ & $63(49.2 \%)$ & $<0.001$ \\
\hline
\end{tabular}

ACI beyond the scope of practice of a PCP. The most frequent indications for an ACI were for a normal saline bolus $(n=14)$ and atropine $(n=7)$. Of the 129 ACPrendezvous cases, there were 34 (26.4\%) patients on whom 48 ACIs were performed. The most frequent ACIs performed were normal saline bolus $(n=29)$ and dopamine $(n=9)$. The median volume of intravenous normal saline infused was $300 \mathrm{ml}$ (range $100-900 \mathrm{ml}$; $\mathrm{IQR}=300 \mathrm{ml}$ ).

Eleven patients $(3 \%)$ had a witnessed cardiac arrest under the care of paramedics. The initial rhythm was ventricular fibrillation/ventricular tachycardia (VF/VT) in eight patients, pulseless electrical activity (PEA) in two patients, and asystole in one patient. All eight patients with a VF/VT cardiac arrest met stable criteria prior to cardiac arrest. Five patients experienced cardiac arrest in the presence of PCPs (all VF/VT). Four of the 11 patients experienced cardiac arrest at the receiving hospital before transfer of care occurred, including 1 who had a cardiac arrest in the elevator. Three of these four patients were managed by PCPs, and all achieved ROSC after either one or two shocks. PCPs also managed and obtained a ROSC in two additional cases prior to a ACP-rendezvous. The two PEA and single asystole patients met unstable criteria prior to a cardiac arrest and experienced an arrest initially in the presence of ACPs. ROSC was achieved in the PEA patients while the asystole patient remained in asystole throughout the resuscitation that included two doses of epinephrine. There were no indications for ACIs or diversion in any PCP-managed cardiac arrest.

For the 42 PCP transports where the closest hospital was also the PCI centre, the median actual transport interval was 3.64 minutes $(\mathrm{IQR}=3.67)$ compared to the median predicted transport interval of 2.89 minutes $(\mathrm{IQR}=4.33)($ Table 4$)$, suggesting that the predicted transport intervals are a reasonable estimate of actual transport intervals. Among 190 patients transported by PCPs where a non-PCI hospital was bypassed, actual and predicted transport intervals from the pickup address to the PCI centre were available for 185 patients. The median actual transport interval to the PCI centre was 10.73 minutes $(\mathrm{IQR}=7.48)$, and the 
median predicted transport interval to the closest nonPCI ED was 5.56 minutes $(\mathrm{IQR}=3.80)$. The median difference in transport intervals between direct PCP bypass and a PCI-centre versus predicted transport interval to the closest $\mathrm{ED}$ was 5.53 minutes $(\mathrm{IQR}=6.71)$.

For the 16 ACP-rendezvous patients whose closest hospital was the PCI centre, the median actual transport interval was 5.52 minutes $(\mathrm{IQR}=2.14)$, and the median predicted transport interval to the PCI centre, not accounting for ACP-rendezvous, was 4.00 minutes $(\mathrm{IQR}=4.66)$. The median difference in the additional transport time incurred by ACP-rendezvous was 1.70 minutes $(\mathrm{IQR}=2.91)$. Among the 113 patients who had an ACP-rendezvous and where a local non-PCI hospital was bypassed, the median actual transport interval to the PCI centre was 14.62 minutes

\begin{tabular}{|c|c|c|}
\hline \multirow[b]{2}{*}{$\begin{array}{l}\text { Medication or } \\
\text { intervention }\end{array}$} & \multirow{2}{*}{$\begin{array}{c}\text { ACP-rendezvous } \\
N \text { performed } \\
\text { (34 of } 129 \\
\text { patients) }\end{array}$} & \multirow{2}{*}{$\begin{array}{l}\text { PCP transport } \\
N \text { indications } \\
\left(19^{\dagger} \text { of } 232\right. \\
\text { patients })\end{array}$} \\
\hline & & \\
\hline All & 48 & 27 \\
\hline Saline bolus & 29 & 14 \\
\hline Atropine & 5 & 7 \\
\hline Dopamine & 9 & 1 \\
\hline Epinephrine & 2 & 0 \\
\hline Amiodarone & 0 & 2 \\
\hline Intubation & 2 & 0 \\
\hline Cardioversion & 0 & 3 \\
\hline Transcutaneous pacing & 1 & 0 \\
\hline \multicolumn{3}{|c|}{$\begin{array}{l}\mathrm{ACl}=\text { advanced care intervention; } \mathrm{ACP}=\text { advanced care paramedic; } \mathrm{PCP}=\text { primary care } \\
\text { paramedic. } \\
\text { "More than one intervention can apply to a single patient. } \\
\text { 'Two additional patients received an intravenous saline bolus by PCPs who had skills in } \\
\text { intravenous insertion. }\end{array}$} \\
\hline
\end{tabular}

$(\mathrm{IQR}=8.60)$. The median predicted transport interval to the closest non-PCI ED was $6.30(\mathrm{IQR}=4.26)$ not accounting for ACP-rendezvous. The median difference in the additional transport time incurred by a combined PCP bypass with an ACP-rendezvous was 7.49 minutes $(\mathrm{IQR}=8.94)$.

\section{DISCUSSION}

Mitigating the risk of death in a patient experiencing a STEMI largely relies on decreasing the total ischemic time. ${ }^{11}$ Over the past decade, this has led to the development of integrated STEMI bypass systems of care, which have demonstrated process improvements ${ }^{5,6,12}$ and have been reported to be associated with a reduction in mortality. ${ }^{13}$

It is obvious that the efficient and safe transport of STEMI patients requires the expertise of prehospital care providers and emergency medical dispatchers. With respect to prehospital care providers, little is known about what expertise is required. Most STEMI bypass programs rely on ACPs, in keeping with the American Heart Association guidelines. ${ }^{7}$ However, this can hinder the development of STEMI bypass programs in communities with no ACPs or create resource stresses in emergency medical services (EMS) systems with a limited number of ACPs.

In September 2015, the Cardiac Care Network of Ontario proposed a STEMI bypass guideline for both PCPs and $\mathrm{ACPs}^{14}$ that has been adopted into the provincial Basic Life Support Patient Care Standards to be implemented in 2017. However, there is a paucity of evidence to support PCP STEMI bypass guidelines. In 2012, Cantor et al. ${ }^{9}$ reported their experience with PCP STEMI bypass in 134 hemodynamically stable patients with a median transport interval of 43 minutes.

\begin{tabular}{|c|c|c|c|c|}
\hline Crew type & Closest hospital & $\begin{array}{l}\text { Median actual transport interval to } \\
\mathrm{PCl} \text { centre in minutes (IQR) }\end{array}$ & $\begin{array}{l}\text { Median predicted transport interval } \\
\text { to closest ED in minutes (IQR) }\end{array}$ & $N$ \\
\hline PCP & $\mathrm{PCl}$ centre & 3.64 (3.67) & $2.89(4.33)$ & 42 \\
\hline PCP & Non- $\mathrm{PCl}$ centre & $10.73(7.48)^{*}$ & $5.56(3.80)^{*}$ & 185 \\
\hline ACP-rendezvous & $\mathrm{PCl}$ centre & $5.52(2.14)^{\dagger}$ & $4.00(4.66)^{\dagger}$ & 16 \\
\hline ACP-rendezvous & Non-PCl centre & $14.62(8.60)^{\ddagger}$ & $6.30(4.26)^{\ddagger}$ & 113 \\
\hline \multicolumn{5}{|c|}{$\begin{array}{l}\mathrm{ACP}=\text { advanced care paramedic; } E D=\text { emergency department; } I Q R=\text { interquartile range; } \\
\mathrm{PCl}=\text { percutaneous coronary intervention; } \mathrm{PCP}=\text { primary care paramedic. } \\
\text { "The median of the case-by-case difference was } 5.53 \text { minutes }(\mathrm{IQR}=6.71) \text {. } \\
\text { The median of the case-by-base difference was } 1.70 \text { minutes }(\mathrm{IQR}=2.91) \text {. } \\
\text { FThe median of the case-by-case difference was } 7.49 \text { minutes (IQR }=8.94) \text {. }\end{array}$} \\
\hline
\end{tabular}


Only one patient had an indication for an acute care intervention. Unfortunately, patients who were diverted during transport to a closer hospital because of acute complications were not reported.

Ryan et al. ${ }^{10}$ demonstrated that, in the absence of a PCP STEMI bypass guideline, the performance of ACIs by ACPs occurred in fewer than $10 \%$ of 342 STEMI patients. The most frequent intervention was administration of morphine for chest pain. Eight (2.3\%) patients experienced cardiac arrest of whom six presented with VF/VT. Lastly, Ross et al. ${ }^{8}$ reported that, in 89 PCP STEMI cases transported to the nearest hospital, the ischemic time could have been decreased by an estimated 50 minutes with direct transport to a PCI centre while only incurring a 7-minute increase in the transport interval. Three $(3.3 \%)$ patients experienced prehospital cardiac arrest, all characterized by $\mathrm{VF} / \mathrm{VT}$.

In the present study, we describe our experience with the implementation of a PCP STEMI bypass guideline that included provisions for an ACP-rendezvous for hemodynamically unstable patients. PCPs followed the STEMI bypass guideline because there was a significant difference in the distribution of stable and unstable patients between PCPs and ACPs, respectively. Overall, the majority of stable patients were transported by PCPs, whereas the transport of unstable patients was evenly distributed between PCPs and ACPs. Importantly, patients with an ACP-rendezvous were more likely to receive an ACI than PCP patients who met indications for an ACI $(26.2 \%$ versus $9.1 \%$, respectively). Our results cannot be equated with PCP compliance with the guidelines, because several patients met unstable criteria where an ACP-rendezvous was requested but was not operationally feasible prior to the PCP arriving at the ED of the PCI centre. Documentation of these requests was inconsistent and therefore not included in our results.

Despite $9.1 \%$ of PCP patients meeting indications for an ACI, no diversion occurred. Of note, the majority (29/48) of the ACIs performed by ACPs were a saline bolus, which may be within the scope of practice of PCPs. Of the 66 stable patients who were transported via an ACP-rendezvous (see Table 2), only seven ACIs were performed in a total of six patients. Six of the ACIs were a saline bolus.

Eleven of 361 patients (3.0\%) experienced a sudden cardiac arrest. Reports suggest that this is predictable in $2 \%$ to $5 \%$ of cases, ${ }^{8,10,15,16}$ most being stable prior to the arrest and presenting with VF. In our study, all patients with VF were resuscitated with one to three shocks, and none required intubation or other ACI. PCPs were successful in resuscitating all cardiac arrest cases that they encountered. Given the unpredictable nature of the onset of cardiac arrest (i.e., 8 of the 11 cardiac arrest events occurred in stable patients), consideration should be given to the prophylactic application of defibrillation pads to all STEMI patients to minimize the time to first shock if a shockable rhythm occurs. ${ }^{17}$

Our findings verify that additional transport time incurred by a STEMI bypass is relatively short compared to transporting STEMI patients to the closest hospital with the need for subsequent interfacility transfer. Typically, the latter approach adds about 50 minutes. ${ }^{8,11,13,18}$ In our setting, the median additional transport time incurred by a direct PCP bypass to a PCI-centre was 5.53 minutes $(\mathrm{IQR}=6.71)$. Our results also suggest that the median additional time incurred by providing an ACP-rendezvous compared to direct PCP bypass is low (7.49 v. 5.53 minutes) when considering hemodynamically unstable patients who are more likely to receive an ACI or experience cardiac arrest characterized by an initial rhythm of PEA or asystole. Overall, our observations provide additional evidence supporting the safety of PCP transport of hemodynamically stable STEMI patients.

\section{LIMITATIONS}

Our experience pertains to an urban setting with short transport intervals where PCPs were trained in 12-lead ECG interpretation and follow a specific guideline. In rural settings with longer transport intervals, the proportion of patients meeting an indication for an ACI may be higher as would be the proportion of patients experiencing a cardiac arrest. Further study using methodology similar to the preliminary report by Cantor $^{9}$ is required to assess the safety of a PCP STEMI bypass in rural settings. Of particular note, Tanguay ${ }^{16}$ has recently described a system facilitating paramedic STEMI bypass in suburban and rural settings with a mean distance from the PCI centre of $50.9 \mathrm{~km}$. Although the scope of practice of the paramedics was not described nor were the indications/ performance of ACIs during transport reported, it serves as a model where the prehospital clinical course of patients could be assessed. ${ }^{16}$ 
We were not able to discern what led to unstable cases being transported by PCPs and stable cases being transported by ACPs. This information would be important for planning and evaluating changes to the guideline used by paramedics.

We did not report the proportion of false positive CODE STEMI activations nor the hospital outcome of our patients because our aim was to reflect upon the experience of paramedics working in the prehospital setting where a definitive diagnosis is not always possible. If one were to compare EMS systems with higher or lower false-positive rates than a particular reference rate, the proportion of patients meeting indications for an ACI or experiencing a cardiac arrest is likely to be lower or higher, respectively.

\section{CONCLUSIONS}

Implementation of the PCP STEMI bypass guideline resulted in a significant difference in the distribution of stable versus unstable patients between PCP versus ACP transport, respectively. Patients transported by ACPs were more likely to receive an ACI compared to PCP patients who met indications for an ACI. PCPs demonstrated an ability to resuscitate cardiac arrest patients and performed a STEMI bypass with only a modest increase in the transport interval compared to transport to the nearest hospital.

Acknowledgements: The authors would like to acknowledge and thank the emergency medical dispatchers and paramedics of Toronto Paramedic Services for their commitment and commendable patient care in their duties of implementing the STEMI bypass guideline, as well as recognize JK for receiving the Comprehensive Research Experience for Medical Students (CREMS) award from the University of Toronto, Faculty of Medicine.

Competing interests: None declared.

\section{REFERENCES}

1. O'Connor RE, Al Ali AS, Brady WJ, et al. Part 9: acute coronary syndrome: 2015 American Heart Association guidelines update for cardiopulmonary resuscitation and emergency cardiovascular care. Circulation 2015;132(Suppl 2): S483-500.

2. O'Gara PT, Kushner FG, Ascheim DD, et al. 2013. ACCF/ AHA guideline for the management of ST-elevation myocardial infarction: a report of the American College of Cardiology Foundation/American Heart Association Task Force on Practice Guidelines. 7 Am Coll Cardiol, 2013(61): e78-140.
3. Drennan IR, Verbeek PR. The role of EMS in regionalized systems of care. CFEM 2015;17:468-74.

4. Sørensen JT, Mæng M. Regional systems-of-care for primary percutaneous coronary intervention in ST-elevation myocardial infarction. Coron Artery Dis 2015;26:713-22.

5. Cheskes S, Turner L, Foggett R, et al. Paramedic contact to balloon in less than 90 minutes: a successful strategy for STEMI bypass to primary PCI in a Canadian emergency medical system. Prehosp Emerg Care 2011;15:490-8.

6. Le May MR, So DY, Dionne R, et al. A citywide guideline for primary PCI in ST-segment elevation myocardial infarction. N Engl 7 Med 2008;358:231-40.

7. O'Connor RE, Brady W, Brooks SC, et al. Part 10: acute coronary syndromes: 2010 American Heart Association guidelines for cardiopulmonary resuscitation and emergency cardiovascular care. Circulation 2010;122(Suppl 3): S787-817.

8. Ross G, Alsayed T, Turner L, et al. Assessment of the safety and effectiveness of emergency department STEMI bypass by defibrillation-only emergency medical technicians/primary care paramedics. Prehosp Emerg Care 2015;19:191-201.

9. Cantor WJ, Hoogeveen P, Robert A, et al. Prehospital diagnosis and triage of ST-elevation myocardial infarction by paramedics without advanced care training. Am Heart $\mathcal{F}$ 2012;164:201-6.

10. Ryan D, Craig AM, Turner L, et al. Clinical events and treatment in prehospital patients with ST-segment elevation myocardial infarction. Prehosp Emerg Care 2013;17:181-6.

11. De Luca G, Suryapranata H, Ottervanger JP, et al. Time delay to treatment and mortality in primary angioplasty for acute myocardial infarction: every minute of delay counts. Circulation 2004;109:1223-5.

12. Cone DC, Lee CH, Van Gelder C. EMS activation of the cardiac catheterization laboratory is associated with process improvements in the care of myocardial infarction patients. Prehosp Emerg Care 2013;17:293-8.

13. LeMay MR, Wells GA, So DY, et al. Reduction in mortality as a result of direct transport from the field to a receiving center for primary percutaneous coronary intervention. 7 Am Coll Cardiol 2012;60:1223-30.

14. Cardiac Care Network of Ontario (CCN). Available at: http://www.ccn.on.ca/ccn_public/uploadfiles/files/Ontario_ STEMI_Protocol_2015.pdf (accessed 18 October 2016).

15. Koeth O, Nibbe L, Arntz HR, et al. for the PREMIR Investigators. Fate of patient with prehospital resuscitation for ST-elevation myocardial infarction and a high rate of reperfusion therapy. Am $\mathcal{F}$ Cardiol 2012;109:1733-7.

16. Tanguay A, Dallair R, Hebert D, et al. Rural patient access to primary percutaneous coronary intervention centers is improved by a novel integrated telemedicine prehospital system. 7 Emerg Med 2016;49:657-64.

17. Osei-Ampofo M, Cheskes S, Byers A, et al. A novel approach to improve time to first shock in prehospital STEMI complicated by ventricular fibrillation. Prehosp Emerg Care 2016;20:278-82.

18. McNamara RL, Wang Y, Herrin J, et al. for the NRMI Investigators. Effect of door-to-balloon time on mortality in patients with ST-segment elevation myocardial infarction. 7 Am Coll Cardiol 2006;47:2180-6. 